\title{
BARREIRAS IDENTIFICADAS EM CONTRATAÇÕES PÚBLICAS SUSTENTÁ VEIS: UMA ANÁLISE DE UMA ORGANIZAÇÃO PÚBLICA BARRIERS IDENTIFIED IN SUSTAINABLE PROCUREMENT: ANALYSIS OF A PUBLIC ORGANIZATION
}

\section{Dalmir Machado Torres Filho ${ }^{1}$}

Marcos Paulo de Oliveira Corrêa ${ }^{2}$

Mariana da Silva Rodrigues ${ }^{3}$

Murilo Cássio Xavier Fahel ${ }^{4}$

\section{Resumo}

A possível crise ambiental levanta questionamentos quanto ao impacto que as escolhas de consumo têm no agravamento do problema ou no apontamento de soluções. Essa questão assume maior relevância quando analisada pelo ponto de vista governamental, um dos grandes consumidores de bens e serviços. No intuito de contribuir com as políticas que visam à utilização do poder de compra do Estado para indução de maior sustentabilidade do mercado, este artigo objetiva identificar as principais barreiras postas à maior utilização das Contratações Públicas Sustentáveis (CPS), no caso do Banco Central do Brasil. Como modelo analítico, utilizou-se revisão bibliográfica e documental quanto à evolução das CPS como alicerce de uma metodologia mista, ou seja, quali-quantitativa, com coleta de dados por meio de entrevistas semiestruturadas e questionários. Os fatores estudados foram priorizados levando em conta o grau em que foram considerados enquanto barreiras e o nível de consenso dessas percepções. Dessa forma, foi possível identificar que os preços mais elevados, a dificuldade de identificar os produtos e serviços mais sustentáveis, a incerteza de alguns demandantes em relação à qualidade desses produtos e a falta de treinamento específico constituem as principais barreiras enfrentadas. Por outro lado, a instituição oferece espaço para realização dessas contratações, os servidores atribuem importância a elas e compreendem o porquê de sua utilização.

Palavras-chave: Compras. Sustentabilidade. Poder de compra. Responsabilidade socioambiental.

Manuscript first received/Recebido em: 27/05/2019 Manuscript accepted/Aprovado em: 10/12/2020

1 Mestrado em Administração Pública pela Fundação João Pinheiro (FJP). Analista no Banco Central do Brasil. Belo Horizonte, Minas Gerais, Brasil. E-mail: dalmir.torres@gmail.com.

2 Mestrado em Administração Pública pela Fundação João Pinheiro (FJP). Administrador na Universidade Federal de Minas Gerais. Belo Horizonte, Minas Gerais, Brasil. E-mail: marcosp.correa@ hotmail.com.

Mestrado em Administração Pública pela Fundação João Pinheiro (FJP). Administradora na Universidade Federal de Minas Gerais. Belo Horizonte, Minas Gerais, Brasil. E-mail: marianasp.adm@ gmail.com.

4 Pós-Doutor na University of Oxford. Doutorado em Ciências Humanas - Sociologia e Política pela Universidade Federal de Minas Gerais (UFMG). Professor na Universidade Estadual de Montes Claros (Unimontes). Montes Claros, Minas Gerais, Brasil. E-mail: murilo.fahel@fjp.mg.gov.br. 


\section{Abstract}

The current environmental crisis raises questions: consumer choices are part of the aggravation of the problem or can pointing solutions. This issue is more relevant when analyzed from the government point of view, one of the biggest consumers of goods and services. In order to contribute to policies aimed at using the state's purchasing power to induce greater market sustainability, this paper aims to identify the main barriers to the increased use of Sustainable Public Procurement (SPC) in the case of the Central Bank of Brazil. As an analytical model, a bibliographical and documentary review of the evolution of SPC was used as a basis for a mixed methodology, that is, qualitative and quantitative, with data collection through semi-structured interviews and questionnaires. The factors studied were prioritized considering the degree to which they were considered barriers and the level of consensus of these perceptions. In this way, it was possible to identify that the higher prices, the difficulty of identifying the most sustainable products and services, the uncertainty of some servants regarding the quality of these products and the lack of specific training are the main barriers faced. On the other hand, the institution offers space for accomplishment of these hirings, the servers attach importance, and they understand the reason for their use.

Keywords: Procurement. Sustainability. Power of purchase. Environmental responsibility.

\section{INTRODUÇÃO}

Tanto no contexto nacional quanto no internacional, progressivamente se aceita a necessidade de reduzir o impacto que bens e serviços têm no meio ambiente e no contexto social. O setor público pode contribuir para essa alteração no padrão de consumo, ao alterar sua forma de contratação, incluindo critérios socioambientais na sua matriz de decisão.

Tendo como embasamento os estudos acadêmicos tradicionais, vinculados à perspectiva econômica, tem-se o processo de compra observado como um instrumento que abastece a administração com os recursos necessários para a consecução de projetos e políticas públicas. Sob o objetivo de efetivar as suas atividades finalísticas, a administração pública faz as compras, que servem como suporte ao desempenho governamental. Para além da condição de atividade-meio, o processo de compra também pode ser entendido como o próprio instrumento da política pública, ao comedir funções do âmbito socioeconômico (CÂMARA; FROSSARD, 2010). O apoio e o incentivo às Contratações Públicas Sustentáveis (CPS) passaram a fazer parte dos parâmetros tradicionais das licitações públicas, configurando a inclusão de fatores socioambientais que promovem não somente a racionalização dos custos, mas também a alavancagem de determinados grupos que se distinguem pelos critérios ambientais que compõem o processo produtivo (OLIVEIRA; SANTOS, 2015).

As CPS, nesse sentido, transformaram-se em relevantes instrumentos de gestão ambiental por parte das instituições públicas, uma vez que critérios de sustentabilidade passaram a ser incluídos nos mecanismos designados à aquisição de bens e contratação de serviços. Ademais, servem de estímulo aos particulares e às pessoas jurídicas de direito privado no que diz respeito à adoção de parâmetros sustentáveis (ALENCASTRO; SILVA; LOPES, 2014). As compras governamentais, nessa perspectiva, podem surtir efeitos sobre os fornecedores e ampliar os investimentos sob a orientação da sustentabilidade, constituindo um importante mecanismo de estímulo ao desenvolvimento sustentável, com efeito direto na iniciativa privada, com repercussões em toda a sociedade (SOUZA; OLIVERO, 2010). 
Na perseguição desse objetivo, o arcabouço legal brasileiro sedimentou, pouco a pouco, a necessidade de inclusão desses critérios sempre que fosse pertinente. A cada norma editada, mais robusto se tornou o argumento. Em 1998, a Lei n. ${ }^{\circ} 9.660$ disciplinou a substituição da frota oficial por veículos movidos a combustível renovável, marcando o início da consideração dos impactos das compras públicas no meio ambiente. Em 2008, a partir da Portaria n. ${ }^{\circ} 61$ do Ministério do Meio Ambiente disciplinou que as licitações realizadas no âmbito desse ministério deveriam observar: "preferência por fornecedores e produtos comprovadamente de menor impacto ambiental”. Já em 2009, a Política Nacional de Mudança do Clima, instituída pela Lei n. ${ }^{\circ}$ 12.187, estabeleceu preferência nas licitações e concorrências públicas para as "propostas que propiciem maior economia de energia, água e outros recursos naturais e redução da emissão de gases de efeito estufa e de resíduos".

Ainda assim, mesmo após vários anos do início desse processo, a realização de CPS ainda se encontra em estado muito incipiente em quase toda a administração pública (ALENCASTRO et al., 2014). Dessa forma, este artigo buscou compreender por que as CPS ainda não se concretizaram de forma mais veemente, levantando a percepção de servidores envolvidos em processos de contratações sobre os principais obstáculos enfrentados. Essa temática tem sido estudada por diversos pesquisadores no país, como na pesquisa de Miranda (2018), Moraes Silva \& Alcobaça (2019).

Para tanto, foram levantadas e discutidas, por meio de métodos quali-quantitativos, as percepções de servidores quanto à existência de obstáculos às CPS, conforme revisão prévia da literatura. A pesquisa foi realizada no Banco Central do Brasil, pois, enquanto é submetido ao mesmo regramento e às políticas federais de aquisições, ou seja, é parte do todo, destaca-se como referência em gestão, incluindo aqui as iniciativas de CPS. Sua administração foi citada como referência em entrevista junto ao TCU, e seu Plano de Gestão de Logística Sustentável (PLS) é utilizado, inclusive, como instrumento de treinamento no curso de CPS promovido pela ENAP. Além disso, o Banco Central se constitui como um órgão central do governo e possui exclusivamente servidores de carreiras do chamado Ciclo de Gestão, denotando sua importância institucional.

\section{FUNDAMENTAÇÃO TEÓRICA}

\subsection{Barreiras à implementação de políticas de contratações públicas sustentáveis}

Segundo Teixeira (2013), mesmo que as instituições expressem a noção de sustentabilidade em sua agenda, as dificuldades de lidar com um conceito transversal e multifacetado podem levar à não efetivação desses princípios. Como a trajetória para inserção das CPS em diversos países e organizações tem várias semelhanças, cabe analisar as barreiras mais comumente enfrentadas em outras experiências. Nesta seção, apresentam-se, portanto, os principais obstáculos observados pela literatura à efetivação das políticas de CPS. Essa discussão permitirá nortear este artigo, analisando a congruência entre os resultados obtidos neste estudo de caso e os demais já obtidos por outras pesquisas de âmbito nacional e internacional. Possibilitará, ainda, um diagnóstico dos pontos frágeis da implementação desenvolvida no caso de um órgão público federal, o Banco Central do Brasil.

Korkmaz (2010), ao estudar os fatores limitadores das CPS na União Europeia, defende que algumas das principais barreiras para a sua realização são: as dificuldades em se mudar o comportamento de compra; a indisponibilidade de fornecedores entregarem esses bens ou serviços; a obscuridade em se contrapor o custo e o valor de avaliação real do dinheiro; a complexidade em se adicionarem fatores mais amplos do que as considerações ambientais; e a noção de que o processo e os resultados alcançados são mais onerosos. Para além dos inúmeros obstáculos legais necessários na implementação 
das CPS, Alencastro et al. (2014) exploram que, no caso brasileiro, é necessário transpor as barreiras que embaraçam a conformidade entre a proposta mais vantajosa para a instituição pública com a possibilidade de promoção do desenvolvimento nacional sustentável.

Inicialmente, cabe definir mais claramente o que são barreiras à implementação de políticas de CPS. Os principais estudos sobre a temática, desde Günther \& Scheibe (2006) até os relatórios avaliativos da ONU, não determinam explicitamente o entendimento sobre barreiras, impedindo uma discussão de variantes conceituais mais aprofundada. O que se depreende pelo estudo sistemático da literatura é a utilização do termo em seu sentido mais comum, como sendo de empecilho, dificuldade. Dessa forma, para fins deste estudo, serão consideradas como barreiras todo fato, percepção ou crença que dificulte, abrande ou impeça a inserção de critérios de sustentabilidade nas compras públicas. Em que pese que os estudos sobre a temática, assim como este, baseiam-se em pesquisas de percepção, sendo, portanto, limitados em seu processo avaliativo quanto à pertinência fática das visões dos atores, estudo como o proposto, no atual estágio de pesquisa sobre o tema, são fundamentais para descortinar vertentes de análise e sinalizar aspectos que devem ser tratados prioritariamente na implementação de políticas de compras públicas sustentáveis.

Brammer \& Walker (2011) foram os primeiros a estudarem, em escala global, os fatores que facilitam e retardam a efetivação das CPS na percepção de funcionários de 280 organizações públicas de diferentes países. Os resultados de seus estudos demonstraram que os fatores dificultadores para implementação das contratações sustentáveis são distintos entre os países pesquisados. Os fatores financeiro e informacional assumiram papéis importantes para quase todos os países. Nesse mesmo sentido, apontaram o Global Review of SPP, os relatórios trienais da ONU sobre a temática. O primeiro deles, datado de 2013, apresenta como principais barreiras enfrentadas pelos países respondentes a percepção de custo mais elevado e a falta de informação sobre as CPS.

Já o relatório publicado em 2017, relativo ao ano de 2016, alterou algumas categorias de respostas, deixando-as condensadas. Ainda assim, a barreira mais citada continuou a ser o custo mais elevado dos produtos mais sustentáveis, e a segunda posição foi ocupada pela falta de expertise na implementação de CPS. Comparando-se os resultados do relatório de 2013 àquele publicado em 2017, têm-se indicativos de como essas barreiras se modificaram ao longo dos anos, mesmo que nem todas as categorias utilizadas nas diferentes pesquisas sejam análogas. A questão dos custos maiores, principal barreira em ambos os anos, apresenta queda de representatividade, chegando a igualar, no último relatório, com a falta de expertise nas CPS, a qual também apresentou queda de $36 \%$ para $33 \%$. Por outro lado, as duas outras categorias comparáveis entre as pesquisas apresentaram alta, quais sejam, carência de legislação e pequena disponibilidade de opções sustentáveis no mercado.

A comparação entre os períodos pode sugerir que as barreiras encontradas pelos países, além de contexto-dependentes, podem ser estágio-dependentes, ou seja, diferentes obstáculos são percebidos a depender do estágio de implantação da política. Por exemplo, um país pode sentir falta da disponibilidade de mais produtos sustentáveis somente depois de construir a expertise necessária para execução das licitações com critérios socioambientais. A verificação dessa hipótese, no entanto, demanda uma série histórica mais ampla e maior comparabilidade entre as categorias, e não será objeto deste estudo. Cabe destacar, no entanto, que a barreira mais apontada pelos países alcança apenas valores próximos a um terço da amostra. Portanto, não é relevante para a maioria dos países, além de indicar que os mecanismos que dificultam a implementação da política tendem a variar nos diferentes locais. 
No âmbito nacional, algumas pesquisas também já foram realizadas buscando compreender as barreiras preponderantes. Couto \& Ribeiro (2016), ao analisar a visão de especialistas sobre o tema, exploram algumas das dificuldades de implementação de políticas de CPS. Entre elas, citam-se: falta de instrumentos confiáveis para avaliar qualidade dos bens; comportamento do servidor de evitar a adição de novas responsabilidades; acúmulo de funções em um único (ou poucos) servidores, impedindo discussões transdisciplinares necessárias às CPS; e necessidade de mais capacitações.

A partir de estudos de casos, pode-se citar ainda a pesquisa de Santos (2011) que avaliou as CPS na Fundação Oswaldo Cruz (Fiocruz), identificando algumas dessas barreiras, mais uma vez destacando a importância do preço das alternativas sustentáveis como limitador da expansão da política. Por fim, também se destaca o trabalho de Teixeira (2013), que, no estudo das barreiras em diversas instituições no estado de São Paulo, encontrou, em posição de relevância, o desconhecimento quanto aos critérios de sustentabilidade, a falta de capacitação dos envolvidos e o preço das alternativas menos danosas.

\section{METODOLOGIA}

Ao selecionar um caso para estudo, torna-se possível aprofundar a análise, permitindo maior crítica e proposição de ações transformadoras (PEREIRA; GODOY; TERÇARIOL, 2009). É o que se propõe: analisar as peculiaridades da dinâmica organizacional e levantar as barreiras que dificultam a realização mais contundente das CPS nessa organização. Segundo Triviños (1987), o caso a ser examinado deve ser parte de um todo e, mais do que isso, tem realce para justificar sua escolha.

Neste artigo, estuda-se o Banco Central do Brasil, parte do Executivo Federal, submetido ao mesmo regramento e às políticas federais, ou seja, é parte do todo. Mas, além disso, destaca-se como referência em gestão, incluindo aqui as iniciativas de CPS. Sua administração foi citada como referência pelo Tribunal de Contas da União (TCU), e seu Plano de Logística Sustentável é utilizado, inclusive, como instrumento de treinamento no curso de CPS promovido pela Escola Nacional de Administração Pública (ENAP). Além disso, o Banco Central se constitui como um órgão central do governo e possui exclusivamente servidores de carreiras do chamado Ciclo de Gestão, denotando sua importância institucional.

Complementarmente, foram realizadas entrevistas não estruturadas com gerentes intermediários e da alta administração nas áreas relacionadas às aquisições, visando contextualizar as respostas recebidas. Estabeleceu-se um grupo focal e 12 entrevistas, totalizando 21 pessoas ouvidas. Tendo sido garantido anonimato aos participantes, cada um deles será identificado ao longo do texto apenas por "E", acrescido de um número aleatório. A realização das entrevistas se deu presencialmente em Belo Horizonte e em Brasília e por telefone nas demais localidades. A escolha dos interlocutores se deu pelo exercício de cargo de gestão em área envolvida com a realização de contratações institucionais. Entre os ouvidos, incluem-se o diretor de Administração do Banco Central do Brasil (DIRAD), servidores do Departamento de Infraestrutura e Gestão Patrimonial (DEMAP) e gerentes administrativos regionais. Além desses, funcionários e exfuncionários do TCU e do Ministério do Planejamento, Desenvolvimento e Gestão (MPOG) foram ouvidos, por terem exercido suas atividades na regulamentação das CPS, no seu acompanhamento e na sua fiscalização. Posteriormente, foram aplicados questionários para servidores diretamente envolvidos com as compras e contratações da instituição. A taxa de resposta dos servidores totalizou $48 \%$ (31 servidores) e os respondentes encontram-se distribuídos nas 10 localidades onde há sedes da instituição.

Para o estudo ora desenvolvido, utilizou-se o modelo conceitual de Gelderman, Ghijsen \& Brugman (2006) na divisão e análise das variáveis, assim como realizado no supracitado estudo de Brammer \& Walker (2011). Esse modelo se esteia na racionalidade individual limitada dos indivíduos (e 
organizações), ou seja, considera que a decisão de agir em prol de uma política depende das informações disponíveis para escolha e da utilidade esperada na implementação da política em relação àquela esperada para manutenção do status quo.

As dimensões utilizadas pelos autores constituem resultados de pesquisas envolvendo agências públicas, instituições acadêmicas, fornecedores do Estado, consultores e advogados, quais sejam: (i) percepção de ineficiência ou custo da política; (ii) a familiaridade com a política; (iii) os incentivos e as pressões organizacionais; e (iv) a resistência dos fornecedores.

Essas dimensões foram utilizadas para decompor a análise das variáveis, sendo, assim, atribuídas, para cada dimensão, as questões realizadas no questionário mais atinentes à sua definição. Cabe ressaltar, ainda, que as questões realizadas provêm de uma adaptação do questionário proposto por Günther \& Scheibe (2006), que estudaram as barreiras à implementação de CPS em diferentes municípios alemães. Sua utilização visa permitir o uso das metodologias analíticas propostas pelos autores para melhor priorização das barreiras encontradas.

A primeira dimensão diz respeito à percepção de ineficiência ou custo da política que, segundo Gelderman et al. (2006), buscava avaliar o impacto da discrepância entre o cumprimento das regras estipuladas e os objetivos priorizados por elas. Trata-se, portanto, da percepção de que os processos estipulados não levam aos resultados propagados. Por exemplo, a proibição de negociação, após o fim do processo licitatório, poderia ser considerada como uma regra ineficiente, e, assim percebida, diminuiria a tendência de cumprimento da diretiva que a contém. Para os efeitos deste artigo, a percepção de ineficiência será tomada de maneira mais ampla, como sendo toda desvantagem atribuída às CPS comparativamente às licitações tradicionais, incluindo aspectos financeiros, de qualidade dos produtos ou aqueles atrelados à maior dificuldade de realização.

Esses aspectos, somados a uma baixa atribuição de valor na utilização das licitações para promoção da sustentabilidade, tendem a formar uma percepção de ineficiência da política e, portanto, a diminuir a probabilidade de sua plena implementação. Ao incluir também aspectos ligados à diferença de custos dos bens e serviços sustentáveis, essa variável absorve a variável "financeiro", explorada por Brammer \& Walker (2011), assumindo especial importância no contexto de restrições orçamentárias e de reavaliação do custo-benefício das políticas públicas. Os autores ressaltam a tendência de maior implementação de políticas de CPS em contextos do tipo ganha-ganha e maior relutância em situações quando os retornos dos custos adicionais são incertos.

A segunda dimensão atrela-se à familiaridade com a política. Gelderman et al. (2006) destacam que o desconhecimento da norma ou a sua falta de clareza aumenta a possibilidade de seu descumprimento, tanto de forma deliberada quanto não deliberada. Para este estudo, além dos aspectos relacionados à construção do arcabouço regulamentador das CPS, serão também considerados como aspectos relacionados a essa dimensão a participação em treinamentos, o conhecimento dos envolvidos sobre os seus objetivos e as potencialidades de sua utilização, bem como sobre os impactos do consumo sobre o meio ambiente. Dessa forma, quanto mais treinamentos forem oferecidos, maior é o conhecimento dos envolvidos sobre as normas reguladoras, a forma de aplicá-las e os objetivos finalísticos da política. Maior será também a tendência de efetivação de uma política de CPS.

A terceira dimensão sinaliza os incentivos e as pressões organizacionais que envolvem as CPS. Gelderman et al. (2006) estabelecem como um dos fatores influenciadores do nível de implementação a percepção dos envolvidos quanto à existência de sanções por descumprimento das regras e a probabilidade de ocorrência delas. Dada a incipiência da política no país, restringe-se esta pesquisa 
quanto à possibilidade de os regulamentos internos das instituições permitirem a realização das CPS. Em um nível mais avançado de implementação, caberia verificar se os regulamentos internos impõem a realização das CPS, para, então, analisar a existência de sanções e a probabilidade de ocorrência delas. Ainda nesse aspecto organizacional, será estudada a percepção de como o processo administrativo tem impactos na realização das CPS, o grau de prioridade atribuída pelo órgão à questão da sustentabilidade e a utilização das CPS para esse fim.

$\mathrm{O}$ último aspecto considerado diz respeito à resistência dos fornecedores. Nesse panorama, espera-se que eles possam atuar como fiscais do cumprimento das normas ligadas às licitações à medida que estas possam lhes beneficiar. Por esse ponto de vista, a falta de conhecimento sobre as normas, por parte de fornecedores potenciais das instituições, diminuiria o efeito desse canal como potencializador da implementação de uma política de CPS. Este artigo não se debruçará sobre essa variável, por não contemplar instrumentos de coletas de dados relacionados aos fornecedores da instituição escolhida para o estudo de caso.

Definidas as dimensões a serem investigadas e classificadas as questões analisadas, cabe esclarecer a forma de construção do instrumento de coleta de dados e a sua aplicação. Cada uma das questões foi estruturada como uma afirmação destacando uma barreira possível ao processo, para o qual os respondentes selecionaram o seu grau de percepção sobre a existência dessa barreira em seu cotidiano, variando a sua resposta entre 1 e 7 (total discordância à total concordância).

No âmbito de pesquisas voltadas para análises de contextos sociais, o uso de métodos qualitativos para a análise dos fenômenos é de suma importância, mesmo não produzindo as generalizações as quais os métodos quantitativos prometem gerar. A pesquisa qualitativa envolve a utilização de ferramentais empíricos, dentre eles o estudo de caso, o qual pretende analisar os momentos, as percepções e os sentidos problemáticos inerentes ao cotidiano dos sujeitos (DENZIN; LINCOLN, 2006). Triviños (1987) aponta a pesquisa qualitativa como capaz de possibilitar a compreensão de fenômenos complexos, trabalhando um universo de significados, motivos, aspirações, crenças, valores e atitudes em busca da compreensão da realidade humana vivida socialmente. Esse questionário foi aplicado no segundo semestre de 2017 aos servidores responsáveis pelas contratações na sede e nas regionais do Banco Central do Brasil, classificando, portanto, este artigo como um estudo de caso.

Os dados coletados foram submetidos a três métodos de análise sucessivos para priorização das barreiras percebidas: o primeiro método de análise foi baseado em percentuais de resposta, considerando o item como obstáculo e os outros dois baseados em análise e setorização gráfica, aos quais são dedicadas subseções específicas; o segundo exercício, por sua vez, trata de categorização das barreiras à implementação por meio de setorização gráfica; por fim, a análise de frequência relativa de respostas semelhantes possibilitou aos pesquisadores insights sobre a importância relativa de cada fator.

Aquelas comuns aos três métodos foram consideradas as prioritárias para aprofundamento das CPS no caso do Banco Central do Brasil. Cada um desses métodos de análise está detalhado separadamente para facilitar a compreensão e apresentada junto aos resultados na próxima seção.

\section{APRESENTAÇÃO E ANÁLISE DOS RESULTADOS}

\subsection{Barreiras percebidas no Banco Central do Brasil}

Neste estudo, a identificação das principais barreiras às CPS se deu pela aplicação sucessiva de três métodos. O primeiro, mais comumente utilizado na literatura, foi baseado em percentuais de resposta, considerando o item como obstáculo e os outros dois baseados em análise e setorização gráfica, aos quais 
são dedicadas subseções específicas. Os resultados compilados do primeiro método são apresentados na tabela a seguir, indicando o percentual de resposta de cada grau da escala, dos quais 1 assinala que o respondente discorda totalmente que o fator constitua uma barreira e 7 concorda totalmente.

Tabela 1 - Percentuais de resposta de grau de concordância com a existência de barreiras às CPS

\begin{tabular}{|c|c|c|c|c|c|c|c|}
\hline Variáveis & 1 & 2 & 3 & 4 & 5 & 6 & 7 \\
\hline As leis são muito complexas & $3 \%$ & $6 \%$ & $13 \%$ & $58 \%$ & $6 \%$ & $6 \%$ & $6 \%$ \\
\hline As leis proíbem as CPS & $13 \%$ & $13 \%$ & $16 \%$ & $32 \%$ & $13 \%$ & $6 \%$ & $6 \%$ \\
\hline Há incerteza sobre a legalidade das CPS & $10 \%$ & $6 \%$ & $13 \%$ & $29 \%$ & $16 \%$ & $23 \%$ & $3 \%$ \\
\hline $\begin{array}{l}\text { Há incerteza quanto ao posicionamento dos } \\
\text { órgãos de controle }\end{array}$ & $10 \%$ & $6 \%$ & $6 \%$ & $35 \%$ & $29 \%$ & $13 \%$ & $0 \%$ \\
\hline Falta treinamento específico & $3 \%$ & $3 \%$ & $10 \%$ & $16 \%$ & $32 \%$ & $13 \%$ & $23 \%$ \\
\hline $\begin{array}{l}\text { Falta de informação sobre o impacto do consumo } \\
\text { sobre o meio ambiente }\end{array}$ & $23 \%$ & $23 \%$ & $19 \%$ & $0 \%$ & $23 \%$ & $10 \%$ & $3 \%$ \\
\hline $\begin{array}{l}\text { Falta de informação sobre as possibilidades de } \\
\text { utilização das CPS }\end{array}$ & $10 \%$ & $16 \%$ & $23 \%$ & $13 \%$ & $10 \%$ & $23 \%$ & $6 \%$ \\
\hline $\begin{array}{l}\text { Falta de informação sobre as alternativas de bens } \\
\text { e serviços mais sustentáveis }\end{array}$ & $10 \%$ & $3 \%$ & $6 \%$ & $19 \%$ & $26 \%$ & $26 \%$ & $10 \%$ \\
\hline Falta de informação sobre o porquê das CPS & $10 \%$ & $10 \%$ & $48 \%$ & $10 \%$ & $19 \%$ & $3 \%$ & $0 \%$ \\
\hline $\begin{array}{l}\text { Sustentabilidade não é um objetivo } \\
\text { organizacional }\end{array}$ & $13 \%$ & $13 \%$ & $29 \%$ & $29 \%$ & $0 \%$ & $6 \%$ & $10 \%$ \\
\hline Manuais internos obstaculizam as CPS & $6 \%$ & $10 \%$ & $32 \%$ & $32 \%$ & $10 \%$ & $10 \%$ & $0 \%$ \\
\hline Falta espaço para realização das CPS & $16 \%$ & $19 \%$ & $55 \%$ & $3 \%$ & $3 \%$ & $3 \%$ & $0 \%$ \\
\hline $\begin{array}{l}\text { Há diferenças de opinião sobre CPS nos } \\
\text { diferentes níveis de decisão }\end{array}$ & $3 \%$ & $3 \%$ & $3 \%$ & $48 \%$ & $13 \%$ & $19 \%$ & $10 \%$ \\
\hline $\begin{array}{l}\text { O processo administrativo existente obstaculiza } \\
\text { as CPS }\end{array}$ & $3 \%$ & $16 \%$ & $13 \%$ & $29 \%$ & $13 \%$ & $10 \%$ & $16 \%$ \\
\hline Servidores não atribuem importância às CPS & $48 \%$ & $23 \%$ & $13 \%$ & $13 \%$ & $3 \%$ & $0 \%$ & $0 \%$ \\
\hline $\begin{array}{l}\text { É difícil identificar as alternativas mais } \\
\text { sustentáveis }\end{array}$ & $0 \%$ & $7 \%$ & $7 \%$ & $23 \%$ & $23 \%$ & $30 \%$ & $10 \%$ \\
\hline $\begin{array}{l}\text { Demandantes têm preconceito contra alternativas } \\
\text { sustentáveis }\end{array}$ & $0 \%$ & $10 \%$ & $10 \%$ & $29 \%$ & $13 \%$ & $32 \%$ & $6 \%$ \\
\hline Produtos sustentáveis são piores & $19 \%$ & $23 \%$ & $16 \%$ & $35 \%$ & $3 \%$ & $3 \%$ & $0 \%$ \\
\hline Produtos sustentáveis são mais caros & $0 \%$ & $0 \%$ & $13 \%$ & $23 \%$ & $29 \%$ & $29 \%$ & $6 \%$ \\
\hline CPS demandam muito trabalho adicional & $3 \%$ & $10 \%$ & $23 \%$ & $26 \%$ & $35 \%$ & $0 \%$ & $3 \%$ \\
\hline Realizar CPS aumentam os custos & $6 \%$ & $0 \%$ & $16 \%$ & $35 \%$ & $19 \%$ & $19 \%$ & $3 \%$ \\
\hline $\begin{array}{l}\text { Não há alternativas sustentáveis suficientes no } \\
\text { mercado }\end{array}$ & $3 \%$ & $3 \%$ & $16 \%$ & $32 \%$ & $23 \%$ & $10 \%$ & $13 \%$ \\
\hline
\end{tabular}

Fonte: Elaborada pelos autores com resultados da pesquisa. 
Para a obtenção dos percentuais, necessários ao primeiro método de priorização, foram consideradas as respostas que identificaram o fator apresentado como uma barreira, ou seja, a proporção de respostas concordantes - respostas 5, 6 e 7 - sobre o total de respondentes. $\mathrm{O}$ dissenso descontextualizado poderia indicar que as questões levantadas por Günther \& Scheibe (2006) e utilizadas neste artigo não foram suficientes para identificar as reais barreiras. Contudo, as principais categorias usadas pela literatura do tema estão representadas no questionário usado e, nas entrevistas não foram citadas barreiras não contempladas pelo instrumento de coleta de dados, sugerindo que a falta de concordância entre os respondentes não se deu por não exaustividade das barreiras potenciais. Além disso, os resultados obtidos em estudos análogos, conforme os mostrados nas seções anteriores, apresentam índices semelhantes. Portanto, mais importante para os fins deste estudo é a análise comparativa entre as barreiras indicando o grau de importância relativa de cada uma delas.

Analisando-se os resultados, categorizados como Gelderman et al. (2006), verificou-se que, na primeira dimensão, ineficiência ou custo da política, $64,5 \%$ dos respondentes acreditam que o preço dos produtos sustentáveis seja uma barreira. Trata-se da segunda mais elevada proporção de respostas concordantes em todo o estudo e a principal referente a essa dimensão. Esse resultado, além de obter consonância com a pesquisa de Brammer \& Walker (2011), também vai ao encontro dos achados de Santos (2011) sobre as CPS na Fiocruz.

Tabela 2 - Proporção de respostas referentes à ineficiência ou custo da política de CPS

\begin{tabular}{lr}
\hline Produtos sustentáveis são mais caros & $64,50 \%$ \\
\hline É difícil identificar as alternativas mais sustentáveis & $61,30 \%$ \\
\hline Demandantes têm preconceito contra alternativas sustentáveis & $51,60 \%$ \\
\hline Não há alternativas suficientes no mercado & $45,2 \%$ \\
\hline Realizar CPS aumenta os custos & $41,90 \%$ \\
\hline CPS demandam muito trabalho adicional & $38,70 \%$ \\
\hline Produtos sustentáveis são piores & $6,50 \%$ \\
\hline Servidores não atribuem importância às CPS & $3,20 \%$ \\
\hline
\end{tabular}

Fonte: Elaborada pelos autores com resultados da pesquisa.

Outra questão, também relacionada à primeira dimensão analisada, abarca a elevação de custos totais pela utilização das CPS, com a qual, nesse caso, apenas 41,9\% dos respondentes concordaram. A diferença de taxa entre essas duas respostas pode indicar que muitos dos servidores participantes da pesquisa já consideram outros custos ao longo do ciclo de vida do produto ou ciclo de execução do serviço, uma das premissas das CPS. Assim, para mais da metade deles, considerando-se todas as despesas envolvidas, o custo não é uma barreira relevante, pois, mesmo que o preço inicial seja maior, ele pode ser descontado ao longo da utilização.

Essa conclusão foi corroborada também por gerentes ao longo das entrevistas realizadas. Por exemplo, o entrevistado E18, sobre o estudo de implantação de geração de energia fotovoltaica, comentou: "esse é um produto caro, mas é um produto que vai se reverter em benefício ao meio ambiente e tem um payback que ainda estamos calculando". Na mesma linha, E41 afirmou que seria justificável pagar mais caro em CPS, mas salientou que ainda falta embasamento sobre o 
quanto mais caro é aceitável. E31 vai mais longe, argumentando no sentido de que as CPS, na verdade, se revertem em economia. Para ele, "[responsabilidade socioambiental] hoje é até uma necessidade porque, em geral, reduz custo". Como último exemplo, E61 resume o argumento salientando que a orientação é comprar pelo melhor preço, não o menor, e o custo-benefício deve ser analisado caso a caso.

Já sobre a segunda dimensão, familiaridade com a política, destacam-se as taxas mais elevadas referentes aos itens relacionados à falta de treinamentos específicos e de informações sobre as alternativas mais sustentáveis, que, de certa forma, reforça ainda mais a carência de treinamento como barreira. A questão da capacitação é elencada como elemento-chave, por exemplo, por Leap (2006), considerando que essa instituição deveria dar formação específica aos colaboradores, tornando-os especialistas em CPS. A percepção de $67,7 \%$ dos respondentes indica que a carência de treinamento pode culminar na ausência de segurança dos compradores em como efetivar as CPS. No mesmo sentido, aponta-se também a elevada taxa de indicação da falta de informações quanto aos dados sobre as alternativas mais sustentáveis, o que, por si só, já poderia ser uma proxy para a escassez de treinamento.

Tabela 3 - Proporção de respostas referentes à familiaridade com política de CPS

\begin{tabular}{ll}
\hline Falta treinamento específico & $67,7 \%$ \\
\hline Falta de informação sobre as alternativas de bens e serviços mais sustentáveis & $61,3 \%$ \\
\hline Há incerteza sobre a legalidade das CPS & $41,9 \%$ \\
\hline Há incerteza quanto ao posicionamento dos órgãos de controle & $41,9 \%$ \\
\hline Falta de informação sobre as possibilidades de utilização das CPS & $38,7 \%$ \\
\hline Falta de informação sobre o impacto do consumo sobre o meio ambiente & $35,5 \%$ \\
\hline As leis proíbem as CPS & $25,8 \%$ \\
\hline Falta de informação sobre o porquê das CPS & $22,6 \%$ \\
\hline As leis são muito complexas & $19,4 \%$ \\
\hline
\end{tabular}

Fonte: Elaborada pelos autores com resultados da pesquisa.

Ressalta-se, contudo, que essa não é a percepção preponderante absorvida pelas entrevistas realizadas com os servidores em exercício nos setores tático-estratégicos da instituição. Para a maior parte deles, os treinamentos de licitação e compras naturalmente deveriam abarcar a questão da inclusão dos critérios de sustentabilidade, não sendo necessários treinamentos específicos. Apenas E21 e E03 argumentaram nesse sentido, sugerindo, inclusive, a necessidade de cursos para apresentação e forma de cálculo de aspectos técnicos ligados à sustentabilidade. Nessa mesma linha, um dos respondentes do questionário salientou: "se houvesse treinamento, poderíamos utilizar mais critérios sustentáveis nas contratações".

Destaca-se, ainda, a questão relacionada ao porquê da inclusão de viés socioambiental nas contratações governamentais. Não foram identificadas barreiras relevantes nesse quesito, indicando que os objetivos da política são bem conhecidos e, além disso, aceitos, visto que somente uma pessoa discordou da importância de realização das CPS, o que representa 3,2\% da amostra. Esse respondente justificou sua opinião voluntariamente no campo de observações do questionário. Ele diz: "vejo a compra sustentável como uma grande falácia que serve apenas para aumentar a burocracia, já bastante avantajada e ineficaz". 
Essa posição mostrou-se minoritária também em relação às entrevistas nas quais a visão mais restritiva ainda era favorável, porém argumentou pela incerteza quanto ao custo-benefício de sua aplicação, levantando a hipótese de que talvez se devesse gastar o mínimo nas contratações e utilizar o recurso economizado para investir diretamente em preservação ambiental, por exemplo.

Tabela 4 - Proporção de respostas referentes aos incentivos e pressões organizacionais

\begin{tabular}{lc}
\hline Há diferenças de opinião sobre CPS nos diferentes níveis de decisão & $41,9 \%$ \\
\hline O processo administrativo existente obstaculiza as CPS & $38,7 \%$ \\
\hline Manuais internos obstaculizam as CPS & $19,4 \%$ \\
\hline Sustentabilidade não é um objetivo organizacional & $16,1 \%$ \\
\hline Falta espaço para realização das CPS & $6,5 \%$ \\
\hline
\end{tabular}

Fonte: Elaborada pelos autores a partir dos resultados da pesquisa.

No que tange à terceira dimensão, incentivos e pressões governamentais, apontou-se para a questão do espaço para a realização das CPS, relacionando-se ao fator cultural e apresentando-se no agregado dos questionários como uma barreira quase inexistente. Para a maioria dos entrevistados, o fato cultural é o mais significativo para o sucesso ou para o fracasso das CPS. E61, inclusive, justifica não ter atribuído tanta importância à questão do treinamento, pois mais fundamental seria a mudança de cultura. Em sua visão, o Banco Central do Brasil tem boa receptividade à questão e, exemplificando com o projeto de substituição de copos descartáveis por canecas, afirmou que a receptividade foi excelente e, apesar de ter ouvido sobre algumas resistências no começo, nunca presenciou nada pessoalmente.

Na opinião de E13, ações de sustentabilidade fazem parte da cultura da instituição há muitos anos, apenas não recebiam esse rótulo. Além disso, muitas das ações tidas como exemplo e pioneirismo de promoção de sustentabilidade em outros órgãos, como os contratos terceirizados de impressão em ilhas, já são consolidadas no Banco Central. Nessa mesma linha segue E17, para quem o Banco Central busca atuar na temática "de maneira caótica, sem uma organização", mas "a sustentabilidade está no nosso dia a dia, a gente faz ações de sustentabilidade, mas não capitaliza. Não faz um trabalho coordenado para medir o quanto a gente tem desenvolvido isso na organização" (E17).

Apesar de os resultados indicarem que a questão cultural no Banco Central do Brasil não deveria se manifestar como uma barreira, podendo até, ao contrário, tornar-se um promotor, pouco mais da metade dos respondentes concordou que os demandantes ainda possuem preconceitos contra alternativas sustentáveis, resultado desalinhado com os argumentos levantados até aqui. Caso essa questão ultrapasse a percepção dos compradores e se verifique como uma opinião dos demandantes, ela poderia ser tratada como prioritária, pois se relaciona tanto com a dimensão informacional já estudada quanto com a de qualidade, apresentada a seguir, e atuar sobre ela compreende três dimensões de barreiras em apenas uma intervenção. Cabe reforçar que o indicador trata da visão sobre a existência de preconceito de outrem contra as alternativas sustentáveis, pois o entendimento dos próprios respondentes, por outro lado, é favorável à qualidade dessas alternativas, tendo sido considerado um problema para apenas $6,5 \%$ dos respondentes, o que corrobora com outros estudos, como o de Teixeira (2013), que encontrou taxa de $5,8 \%$ para o mesmo item. 
Relacionando tanto os aspectos culturais quanto a priorização das CPS na instituição, destacam-se ainda outras duas questões. A primeira diz respeito aos servidores concordarem que a sustentabilidade não é perseguida como um objetivo organizacional e a outra se relaciona à ausência de espaço para realização das CPS. Ambos os resultados obtiveram baixo índice de concordância, $16,1 \%$ e $6,5 \%$, respectivamente, revelando que a priorização assim definida não seria uma barreira para a implantação das CPS. Essa análise dialoga com a variável "falta de apoio institucional", segunda mais relevante encontrada por Cypreste (2013), e no Banco Central do Brasil não se mostra como uma barreira percebida.

A análise de frequência de respostas semelhantes possibilita insights sobre a importância relativa de cada fator. Contudo, outros métodos que possibilitam um exame mais completo dos dados, levando-se em conta também as respostas discordantes e a dispersão desses dados, são capazes de melhor informar uma priorização. Assim, a fim de verificar os dados, utilizou-se de forma adaptada o método desenvolvido por Günther \& Scheibe (2006), originalmente, para levantamento das barreiras à implementação de contratações sustentáveis nos municípios alemães. Nesse modelo analítico, os respondentes são inqueridos sobre o grau de concordância em relação a obstáculos previamente selecionados na literatura sobre o tema. Os dados resultantes são, então, analisados conforme o nível aferido e a dispersão de resposta.

Dessa forma, os resultados obtidos pelos questionários foram tabulados e utilizados para classificar os obstáculos levantados de acordo com a percepção dos entrevistados quanto a sua relevância. Para isso, foram analisadas a média e a homogeneidade de resposta através do desvio padrão. Segundo Günther \& Scheibe (2006), diferenças acentuadas de percepção são de especial importância para identificar barreiras que podem consistir em simples falta de informação ou ainda para sinalizar possíveis problemas de resistência à implementação por parte de alguns atores. Para essa análise, dois exercícios foram realizados.

O primeiro consiste na utilização de box plots, o que permite uma análise gráfica quanto à percepção média das barreiras e sua dispersão entre os entrevistados. Esse método de avaliação com base nas médias e seus desvios é válido para dados cardinais sob o pressuposto de que os dados são equidistantes, o que é uma exigência preenchida pela própria concepção do questionário, de acordo com Rohrmann (1978). O segundo exercício, por sua vez, trata de categorização das barreiras à implementação por meio de uma adaptação da setorização gráfica proposta por Günther \& Scheibe (2006), através de um gráfico de dispersão no qual o eixo vertical representa a nota média atribuída à barreira e o outro o desvio padrão dessa nota.

Conforme adiantado, esse método consiste na construção de gráficos box plots, que possibilitam análise visual da média e mediana de resposta, além de apresentar a característica de distribuição da amostra. Quanto mais nos extremos estiver localizada e menor for a caixa, mais congruente é a percepção de que a questão se constitui como um obstáculo. Quanto maiores forem a caixa e as hastes, mais divergente é a percepção em relação à existência daquele obstáculo. Os resultados estão apresentados nos gráficos a seguir. As questões foram mais uma vez divididas entre as dimensões categorizadas por Gelderman et al. (2006). 
Gráfico 1 - Box plot sobre percepção de barreiras referentes à ineficiência ou custo da política

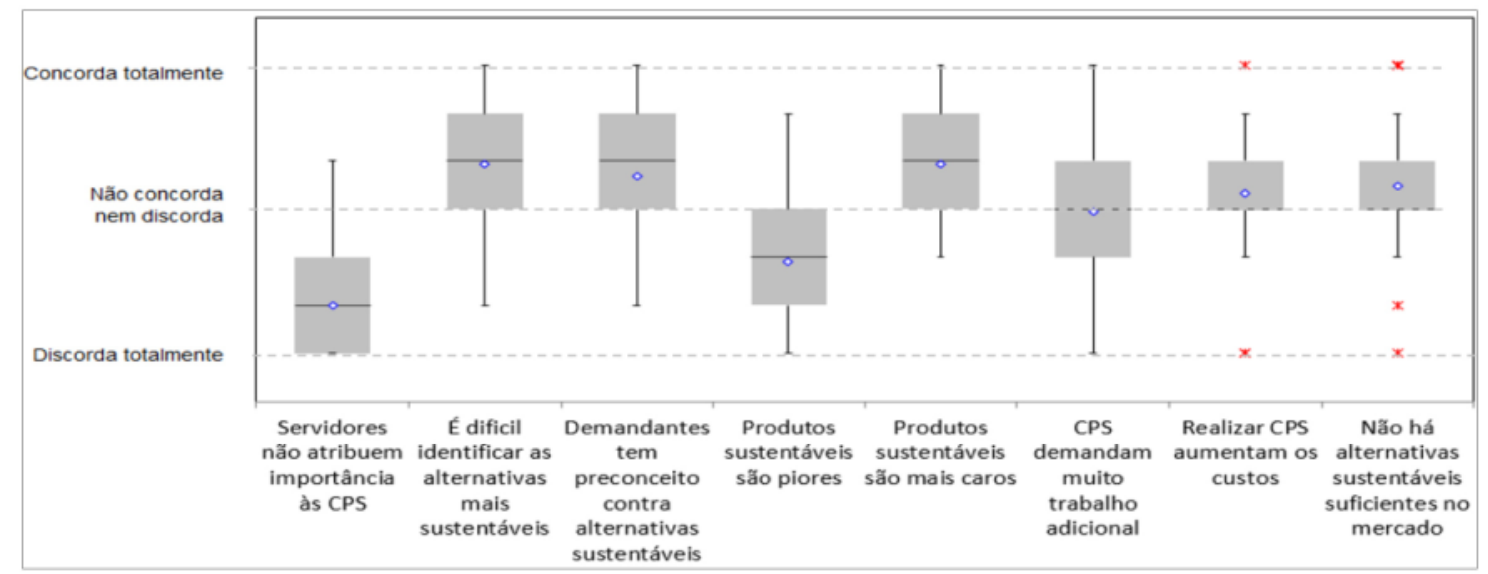

Fonte: Elaborado pelos autores a partir dos resultados da pesquisa.

A análise gráfica permite identificar maior homogeneidade de resposta referente à importância atribuída pelos servidores às CPS e à não percepção de qualidade inferior dos produtos sustentáveis, indicando que essas questões provavelmente não constituem barreiras relevantes e não devem ser tratadas como prioridades de intervenção. Por outro lado, confirmando a análise preliminar, são barreiras mais pertinentes à dificuldade de identificação de alternativas sustentáveis, o preconceito dos demandantes e o preço. Ao contrário do que indica a análise preliminar, o custo total das CPS ainda pode representar uma barreira percebida, dada baixa quantidade de servidores que discordaram da existência dessa barreia, em comparação com os indefinidos e os concordantes. No grupo de questões mais relacionadas à familiaridade com a política, o grau de concordância foi ainda menor, havendo respostas entre os extremos, como pode ser observado a seguir.

Gráfico 2 - Box plot sobre percepcão de barreiras referentes à familiaridade com a política

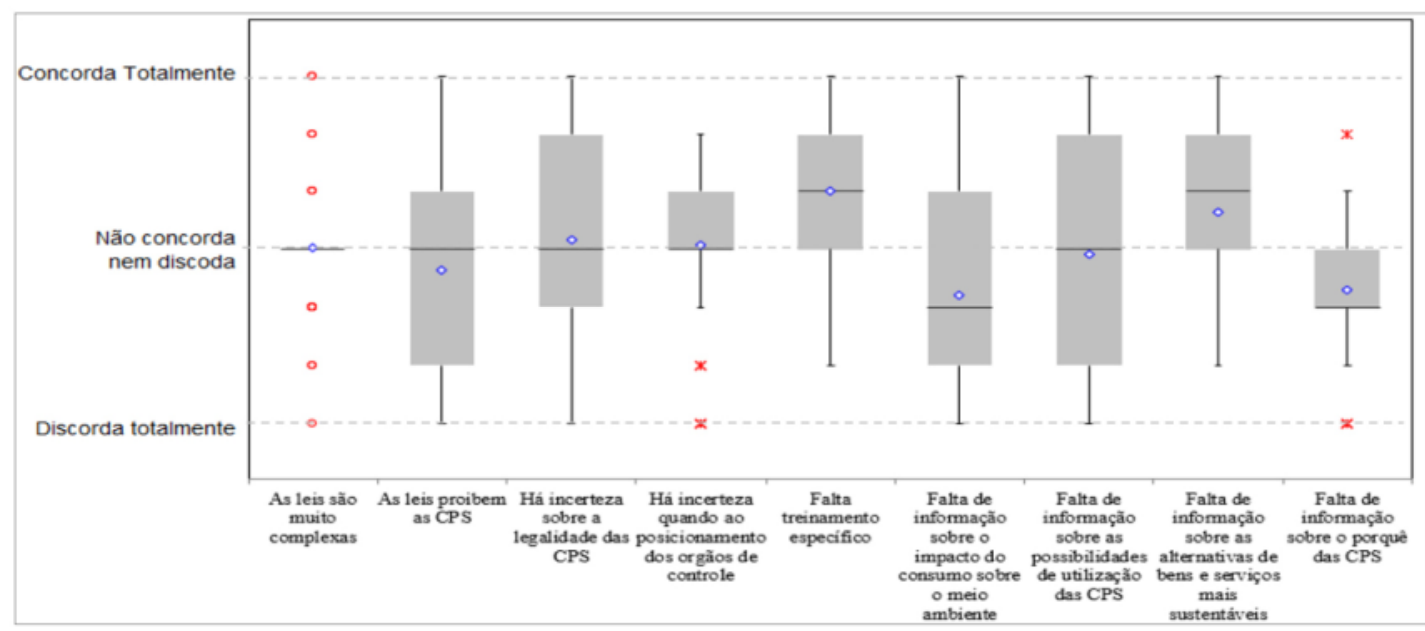

Fonte: Elaborada pelos autores a partir dos resultados da pesquisa.

A percepção sobre a proibição legal às CPS, a falta de informação sobre os impactos do consumo no meio ambiente, as possibilidades de utilização das CPS e a complexidade das leis relacionadas à temática oscilaram entre a total discordância e a total concordância. Por outro lado, aparecem, com significativa homogeneidade, a incerteza de posicionamento dos órgãos de controle, a falta de treinamentos específicos e a ausência de informações sobre as alternativas mais sustentáveis, estas 
duas últimas também confirmando a análise preliminar realizada. A falta de importância atribuída às CPS não parece se constituir um problema, como igualmente apontado preliminarmente.

A incerteza sobre a legalidade das CPS apresenta também um deslocamento no sentido da configuração de uma barreira. Sobre esse ponto, destaca-se o alerta feito por Betiol et al. (2012), segundo os quais parte das mudanças necessárias para implementação das CPS, que são dependentes de ações voluntárias, motivadas por consciência social e ambiental individual, não ocorre sob alegação de impedimentos legais para sua realização. Por fim, analisam-se as questões restantes, mais atinentes aos incentivos e pressões institucionais. Os resultados são apresentados a seguir, na forma de box plots.

Gráfico 3 - Box plot sobre percepção de barreiras referentes aos incentivos e pressões institucionais

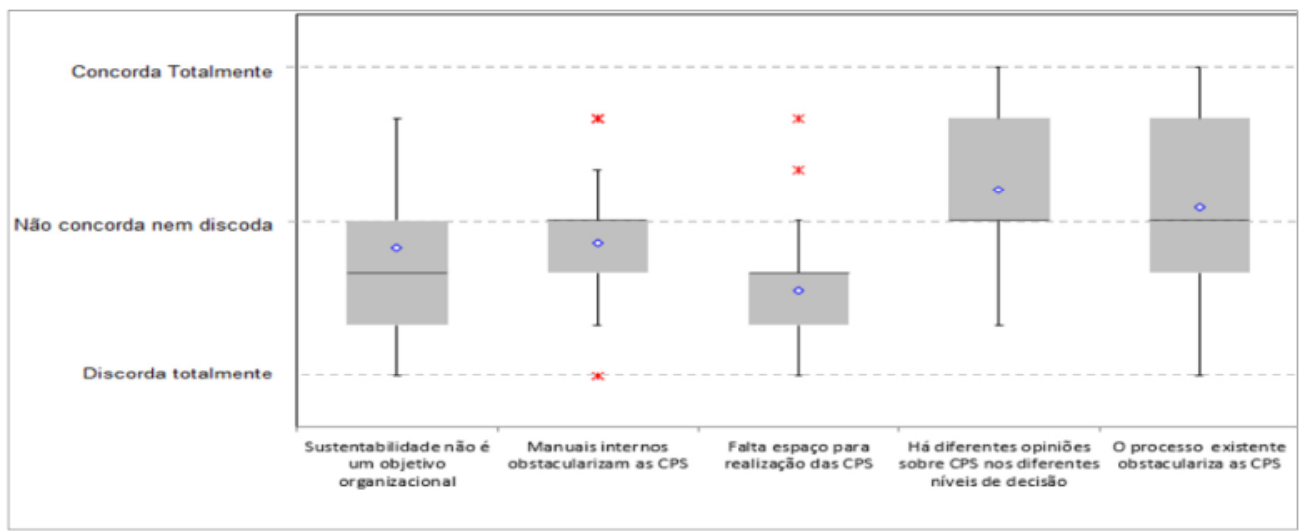

Fonte: Elaborado pelos autores a partir dos resultados da pesquisa.

Esse grupo de questões contém aquela com o maior grau de concordância, qual seja, a existência de espaço para realização das CPS, indicando que esse fator não se constitui como barreira. Da mesma forma, porém com menor intensidade, encontram-se a definição de busca por sustentabilidade como objetivo organizacional e a adequação dos manuais internos para aplicação das CPS. Como potencial obstáculo, assim como na análise inicial, identifica-se a divergência de opinião sobre CPS nos diferentes níveis de decisão. Os obstáculos relacionados com o apoio institucional, tal como este, tornam-se de especial relevância, pois, segundo Teixeira (2013), quando não há diretrizes explícitas relativas ao compromisso da organização e da administração superior com o uso das CPS, os compradores não se sentem à vontade para inovar, o que mina as iniciativas de concretização do instrumento.

Em suma, examinando-se o conjunto das análises, percebe-se que os itens mais claramente estabelecidos como barreiras nessa metodologia foram: o preço, a dificuldade de identificação, o preconceito dos demandantes, a falta de alternativas no mercado, os custos envolvidos, a carência de treinamento específico, a ausência de informações sobre os bens sustentáveis, a incerteza sobre o posicionamento dos órgãos de controle e a diferença de opiniões nos diferentes níveis organizacionais. Essa metodologia mostrou-se, portanto, com maior sensibilidade do que a baseada em percentual de respostas negativas. Isso se dá pela análise da distribuição de resposta em todas as categorias de resposta, o que não ocorre no primeiro método.

A última análise realizada trata da categorização dos obstáculos através da setorização do gráfico de dispersão média versus desvio, estudo esse também inspirado em Günther \& Scheibe (2006). Nesse gráfico, quanto mais à esquerda o ponto, menor a divergência de opiniões; e quanto mais acima, mais essa opinião vai no sentido da questão se constituir como barreira à implementação das CPS. Com essa lógica, os autores delimitam três regiões do gráfico com significados em termos da sua relevância. A 
área central, denominada na Figura 1 como Selection, compreende os resultados que ficaram próximos do "não concordo nem discordo" e com maior divergência. Assim, pouco pode ser dito a priori sobre o impacto dessas questões no processo de implementação das CPS.

Figura 1 - Setorização gráfica das variáveis conforme modelo desenvolvido por Günther \& Scheibe (2006)

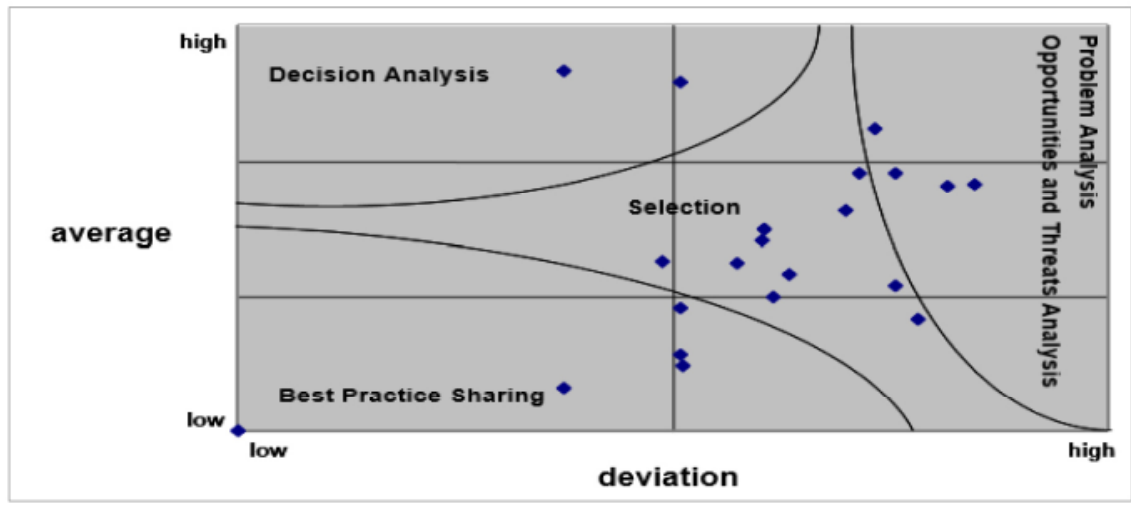

Fonte: Günther, \& Scheibe, 2006.

Para os autores, o setor Best Practice Sharing concentra os fatores que não se constituem como uma barreira para a organização, e uma ação possível é a difusão das práticas relacionadas para aqueles que ainda enfrentem esses problemas. Nesse setor os entrevistados tiveram alta concordância sobre a não relevância do fator como obstáculo. O setor Decision Analysis, por outro lado, abarca os fatores que os respondentes mais concordaram sobre sua relevância. Constituem, assim, as principais barreiras sobre as quais os gestores podem planejar e agir. As seções Problem Analysis e Opportunities and Threats Analysis abrangem os fatores que, independentes da avaliação média de relevância como barreira, tiveram alta discordância entre os respondentes, revelando possíveis assimetrias informacionais e de opinião que poderiam ser solucionadas com maior difusão de conhecimento ou programas de sensibilização.

Neste estudo, a fim de dar maior objetividade à setorização, optou-se por delimitar os setores através de retas. No sentido horizontal, traçaram-se linhas com 0,5 para mais e para menos da média, setorizando as respostas centrais do gráfico, aquelas em que os servidores em média não formaram juízo se a questão constituía ou não uma barreira às CPS. No sentido vertical, traçaram-se retas dividindo o eixo em quatro. Após a setorização, buscou-se analogia com o trabalho de Günther e Scheibe (2006), assim a área hachurada equivaleria ao setor Selection, que delimita os outros três setores, em posição equivalente ao trabalho original.

O Gráfico 4 apresenta esses resultados. Nele seis questões ficaram categorizadas no setor Decision Analysis e constituiriam as prioridades para ação em prol de uma implantação mais ampla das CPS no Banco Central do Brasil, quatro delas localizam-se no setor Best Practice Sharing e podem ser consideradas obstáculos vencidos. Por fim, duas foram plotadas na área Problem Analysis/ Opportunities and Threats Analysis e demandarão análise mais aprofundada em estudos posteriores. 
Gráfico 4 - Dispersão média versus desvio padrão e setorização adaptada de Günther \& Scheibe (2006)

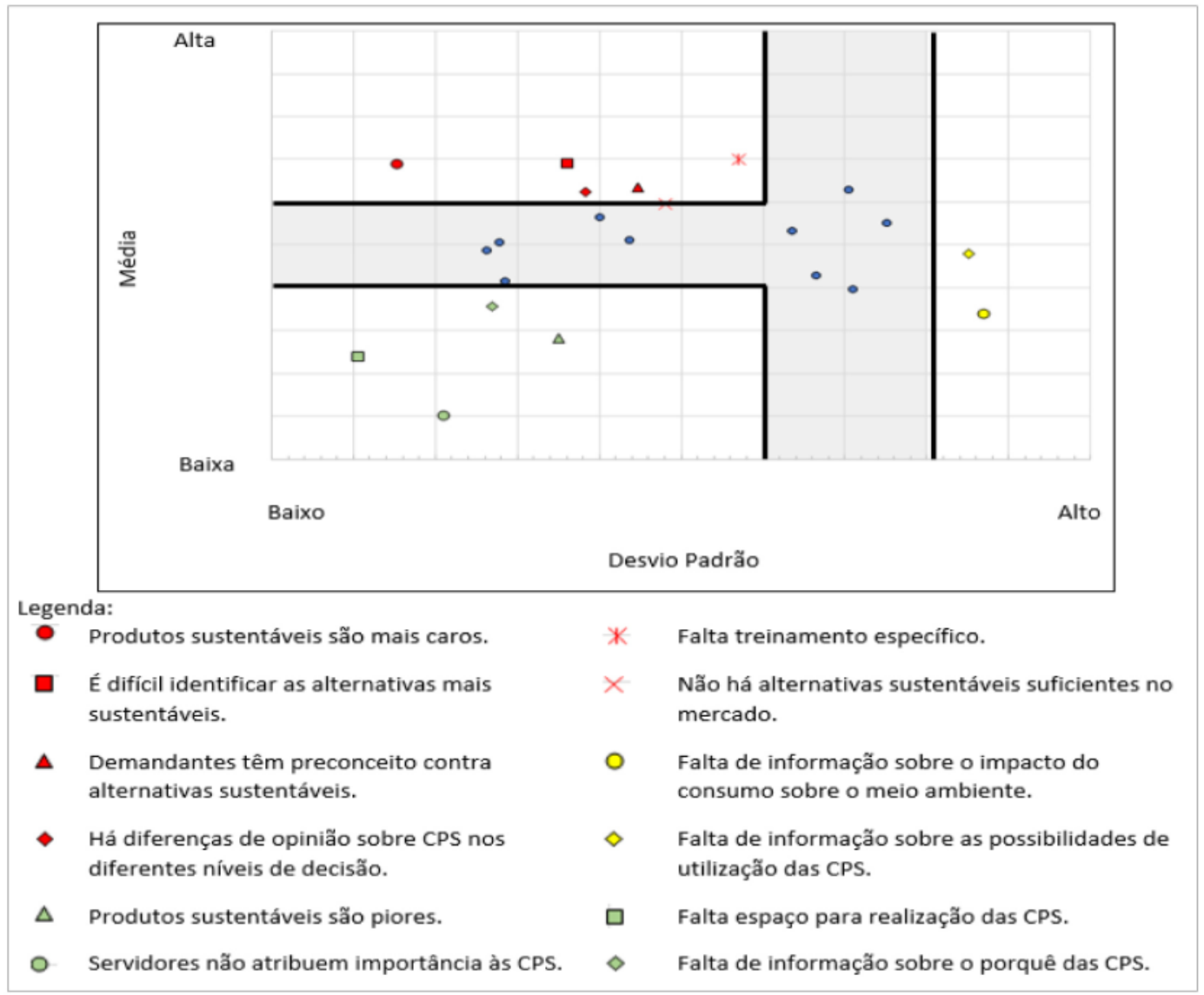

Fonte: Elaborado pelos autores a partir dos resultados da pesquisa.

Analisando conjuntamente as três metodologias, pôde-se obter o quadro a seguir, que demonstra as barreiras identificadas em cada uma das metodologias, representando quais são as mais relevantes e quais devem ser priorizadas.

Quadro 1 - Maiores e menores obstáculos reconhecidos por metodologia

\begin{tabular}{|l|c|c|c|}
\hline \multicolumn{1}{|c|}{ Barreira percebida } & Percentual & Box plot & $\begin{array}{c}\text { Setorização } \\
\text { gráfica }\end{array}$ \\
\hline Produtos sustentáveis são mais caros & $\mathrm{x}$ & $\mathrm{x}$ & $\mathrm{x}$ \\
\hline É difícil identificar as alternativas mais sustentáveis & $\mathrm{x}$ & $\mathrm{x}$ & $\mathrm{x}$ \\
\hline $\begin{array}{l}\text { Demandantes têm preconceito contra alternativas } \\
\text { sustentáveis }\end{array}$ & $\mathrm{x}$ & $\mathrm{x}$ & $\mathrm{x}$ \\
\hline Não há alternativas suficientes no mercado & & $\mathrm{x}$ & \\
\hline Realizar CPS aumentam os custos & & & \\
\hline CPS demandam muito trabalho adicional & & & \\
\hline Produtos sustentáveis são piores & & $\mathrm{x}$ & $\mathrm{x}$ \\
\hline Servidores não atribuem importância às CPS & $\mathrm{x}$ & $\mathrm{x}$ \\
\hline Falta treinamento específico & & & \\
\hline Falta de informação sobre as alternativas mais sustentáveis & $\mathrm{x}$ & \\
\hline Há incerteza sobre a legalidade das CPS & & \\
\hline
\end{tabular}

\section{5}




\begin{tabular}{|l|l|l|l|}
\hline $\begin{array}{l}\text { Há incerteza quanto ao posicionamento dos órgãos de } \\
\text { controle }\end{array}$ & $\mathrm{x}$ & \\
\hline $\begin{array}{l}\text { Falta de informação sobre as possibilidades de utilização } \\
\text { das CPS }\end{array}$ & & & \\
\hline $\begin{array}{l}\text { Falta de informação sobre o impacto do consumo sobre o } \\
\text { meio ambiente }\end{array}$ & & & \\
\hline As leis proíbem as CPS & & & \\
\hline Falta de informação sobre o porquê das CPS & & & \\
\hline As leis são muito complexas & & $\mathrm{x}$ \\
\hline $\begin{array}{l}\text { Há diferenças de opinião sobre CPS nos diferentes níveis } \\
\text { de decisão }\end{array}$ & & & \\
\hline O processo administrativo existente obstaculiza as CPS & & & \\
\hline Manuais internos obstaculizam as CPS & & & \\
\hline Sustentabilidade não é um objetivo organizacional & & & \\
\hline Falta espaço para realização das CPS & & & \\
\hline
\end{tabular}

Fonte: Elaborado pelos autores a partir dos resultados da pesquisa.

Pela análise do quadro, percebe-se a congruência de resultados entre os modelos analíticos das quais se destacam quatro fatores indicados por todas como prioritários: o preço, a dificuldade de identificação, o preconceito dos demandantes e a falta de treinamento específico. Esses dois últimos demonstraram-se como mais claramente tratáveis no ambiente organizacional, sendo possível atuar já no curto prazo de maneira independente da política nacional.

Este artigo contribuiu para uma reflexão quanto aos motivos das CPS ainda não terem sido concretizadas de forma mais veemente, levantando em consideração a percepção de servidores envolvidos em processos de contratações sobre os principais obstáculos enfrentados. Por meio de métodos quali-quantitativos, as percepções de servidores quanto à existência de obstáculos às CPS, permitiram uma atualização da literatura sobre o tema.

\section{CONCLUSÃO}

As CPS transformaram-se em relevantes instrumentos de gestão ambiental por parte das instituições públicas, uma vez que critérios de sustentabilidade passaram a ser incluídos nos mecanismos designados à aquisição de bens e contratação de serviços. As compras governamentais, nessa perspectiva, podem surtir efeitos sobre os fornecedores e ampliar os investimentos sob a orientação da sustentabilidade, constituindo um importante mecanismo de estímulo ao desenvolvimento sustentável. $\mathrm{O}$ arcabouço legal brasileiro sedimentou, pouco a pouco, a necessidade de inclusão desses critérios sempre que fosse pertinente. A cada norma editada, mais robusto se tornou o argumento. Mesmo assim, após vários anos do início desse processo, a realização de CPS ainda se encontra em estado muito incipiente em quase toda a administração pública.

$\mathrm{O}$ apoio e o incentivo às CPS passaram a fazer parte dos parâmetros tradicionais das licitações públicas, porém ainda configuram um estado incipiente em quase toda a administração pública. Mesmo que já vislumbradas como relevantes instrumentos de gestão ambiental, por parte das instituições públicas e em benefício da sociedade, as CPS ainda se deparam com barreiras que trazem dificuldades de se lidar com um conceito transversal e multifacetado, contribuindo para a não efetivação dos seus princípios.

\section{6}


No caso do Banco Central do Brasil, mesmo que, muitas vezes justificadas por critérios econômicos, há o histórico de experiências de sustentabilidade já bem consolidadas. Além disso, a instituição enuncia a responsabilidade socioambiental como prioridade estratégica da entidade e dá espaço suficiente para a realização das CPS. Essas constatações contrastam-se com o nível ainda pequeno de contratações realizadas com viés sustentável. De acordo com a pesquisa, na percepção dos servidores, isso se justifica, em especial, pelo preço mais elevado desses produtos, pela dificuldade de identificar os produtos e serviços mais sustentáveis, pela carência de treinamentos específicos e pelo preconceito por parte de alguns demandantes que resistem a alternativas com esse apelo.

Transpondo-se os resultados para o modelo utilizado de Gelderman et al. (2006), concluise que, no caso do Banco Central do Brasil, os principais obstáculos à efetivação da política encontram-se mais atrelados à percepção de custos e/ou ineficiência da política, e menos aos incentivos e pressões organizacionais que ofereceriam ambiente propício para a realização das CPS. Quanto à familiaridade, os servidores compreendem a importância da política, as relações entre o consumo e o impacto ambiental, mas ainda carecem de know-how sobre como, na prática, introduzir os critérios socioambientais.

É fundamental que se aprofundem estudos sobre as barreiras identificadas nas contratações públicas sustentáveis. Sugere-se estudos mais aprofundados dimensões e resultados evidenciados nesta pesquisa, problematizando as suas relações com os outros aspectos e delimitando os personagens presentes nesse contexto organizacional. Dessa forma, esta pesquisa abre novos espaços para serem investigados.

\section{REFERÊNCIAS}

ALENCASTRO, Maria Alice Cruz; SILVA, Edson Vicente da; LOPES, Ana Maria D.’Ávila. Contratações sustentáveis na administração pública brasileira: a experiência do Poder Executivo federal. Revista de Administração Pública, São Paulo, v. 48, n.1, p. 207-235, 2014.

BETIOL, Luciana Stocco et al. Compra sustentável: a força do consumo público e empresarial para uma economia verde e inclusiva. São Paulo: FGV, 2012.

BRAMMER, Stephen; WALKER, Helen. Sustainable procurement in the public sector: an international comparative study. International Journal of Operations \& Production Management, v. 31, n. 4, 452-476, 2011.

CÂMARA, Leonor M.; FROSSARD, Leila B. de M. Poder de compras da administração pública federal: novas perspectivas para o debate acadêmico. In: ENCONTRO DE ADMINISTRAÇÃO PÚBLICA E GOVERNANÇA, 5, 2010, p. 2-16. Anais [...]. Vitória, ES: EnAPG, 2010.

CYPRESTE, Aline Silva Tavares. Licitações sustentáveis, instrumento legal de promoção da sustentabilidade: um estudo da aquisição de bens na Universidade Federal do Espírito SantoUFES. 2013. Dissertação (Mestrado em Administração Pública) - Universidade Federal do Espírito Santo, Vitória, 2013. 
COUTO, Hugo Leonnardo Gomides do; RIBEIRO, Francis Lee. Objetivos e desafios da política de compras públicas sustentáveis no Brasil: a opinião dos especialistas. Revista de Administração Pública, Rio de Janeiro, v. 50, n. 2, p. 331-343, 2016.

DEZIN, Norman K.; LINCOLN, Yvonna S. (orgs). O planejamento da pesquisa qualitativa: teorias e abordagens. 2. ed. Porto Alegre: Artmed, 2006, 432 p.

GELDERMAN, Cees J. et al. Public procurement and EU tendering directives-explaining noncompliance. International Journal of Public Sector Management, v. 19, 702-714, 2006.

GÜNTHER, Edeltraud; SCHEIBE, Lilly. The hurdle analysis. A self evaluation tool for municipalities to identify, analyse and overcome hurdles to green procurement. Corporate Social Responsibility and Environmental Management, v. 13, n. 2, p. 61-77, 2006.

ICLEI - LOCAL GOVERNMENTS FOR SUSTAINABILITY. The Procura+ Manual: a guide to cost-effective sustainable public procurement. 2 Ed. Freiburg: ICLEI European Secretariat GmbH, 2007. Disponível em: http://www.buysmartbc.com/ Library/Resources/resource iclei procura manual.pdf. Acesso em: 16 nov. 2016

KORKMAZ, Abdullah. Benefits and obstacles of environmental: social and sustainable procurement. Seul: IPPC4, 2010.

\section{LEAP - LOCAL ENVIRONMENTAL MANAGEMENT SYSTEMS AND PROCUREMENT.} General Introduction. LEAP GPP Toolkit, 2006. Disponível em: http://www.leap-gpp-toolkit.org/ index.php?id=99. Acesso em: $28 \mathrm{dez} .2016$

MIRANDA, Nara Oliveira. Compras públicas sustentáveis: barreiras e oportunidades de melhoria no âmbito das organizações militares da Marinha. 2018. Dissertação (Mestrado em Administração Pública) - Escola Brasileira de Administração Pública e de Empresas, Rio de Janeiro, Brasil, 2018.

MORAES SILVA, A. M.; ALCOBAÇA, J. M. G. Barreiras na implementação da política de compras públicas sustentáveis. Revista FSA, Teresina, PI, v. 16, n. 5, p.203-224, 2019.

DE OLIVEIRA, Bernardo Carlos SCM; SANTOS, Luis Miguel Luzio dos. Compras públicas como política para o desenvolvimento sustentável. Revista de Administração Pública, Rio de Janeiro, v. 49, n. 1, p. 189-206, 2015.

PEREIRA, L. DE T. K; GODOY, D. M. A.; TERÇARIOL, D. Estudo de caso como procedimento de pesquisa científica: reflexão a partir da clínica fonoaudiológica. Psicol. Reflex. Crit., Porto Alegre, RS, v. 22, n. 3, p.422-429, 2009. Disponível em: http://www.scielo.br/scielo.php?script=sci_ arttext\&pid=S0102-79722009000300013\&lng=en\&nrm=iso. Acesso em: 8 ago. 2017. 
SANTOS, R. M. T. Compras públicas sustentáveis: a utilização do poder de compra do Estado no fomento de produtos ecologicamente corretos na Fiocruz. 2011. Dissertação (Mestrado em Saúde Pública) - Escola Nacional de Saúde Pública Sergio Arouca, Fundação Oswaldo Cruz, Rio de Janeiro, 2011.

SOUZA, Maria T.S de; OLIVERO, Simone M. Compras Públicas Sustentáveis: um estudo da incorporação de critérios socioambientais nas licitações do governo do Estado de São Paulo. In: ENCONTRO DA ASSOCIAÇÃO NACIONAL DE PÓS-GRADUAÇÃO E PESQUISA EM ADMINISTRAÇÃO, 34, 2010. Anais [...]. Rio de Janeiro: ANPAD, 2010.

TEIXEIRA, Maria Fernanda de Faria Barbosa. Desafios e oportunidades para a inserção do tripé da sustentabilidade nas contratações públicas: um estudo dos casos do Governo Federal Brasileiro e do Governo do Estado de São Paulo. 2014. Dissertação (Mestrado em Desenvolvimento Sustentável) - Universidade de Brasília, Brasília, DF, 2013. Disponível em: http://www.repositorio.unb.br/ bitstream/10482/13866/1/2013 MariaFernandadeFariaBarbosaTeixeira.pdf. Acesso em: 19 jan. 2018

TORRES FILHO, Dalmir Machado. Contratações públicas sustentáveis: o caso do Banco Central do Brasil. 2018. Dissertação (Mestrado em Administração Pública). Programa de Pós-Graduação em Administração Pública, Fundação João Pinheiro, Belo Horizonte, MG, 2018.

TRIVIÑOS, Augusto Nibaldo Silva. Introdução à pesquisa em ciências sociais: a pesquisa qualitativa em educação. São Paulo: Atlas, 1987.

UNEP - UNITED NATIONS ENVIRONMENT PROGRAMME. Global Review of Sustainable Public Procurement. 2013. Disponível em: https://www.globalecolabelling.net/assets/Documents/ unep-spp-report.pdf. Acesso em: 20 jan. 2018.

UNEP - UNITED NATIONS ENVIRONMENT PROGRAMME. Global Review of Sustainable Public Procurement. 2017. Disponível em: https://wedocs.unep.org/bitstream/ handle/20.500.11822/20919/GlobalReview Sust Procurement.pdf?sequence=1\&isAllowed=y. Acesso em: 20 jan. 2018.

\section{Dados dos autores:}

\section{Dalmir Machado Torres Filho}

ORCID: https://orcid.org/0000-0003-3305-5676

Mestrado em Administração Pública pela Fundação João Pinheiro (FJP). Analista no Banco Central do Brasil. Belo Horizonte, Minas Gerais, Brasil. E-mail: dalmir.torres@ gmail.com.

\section{Marcos Paulo de Oliveira Corrêa}

ORCID: https://orcid.org/0000-0002-7186-6624

Mestrado em Administração Pública pela Fundação João Pinheiro (FJP). Administrador na Universidade Federal de Minas Gerais. Belo Horizonte, Minas Gerais, Brasil. E-mail: marcosp.correa@hotmail.com. 


\section{Mariana da Silva Rodrigues}

ORCID: https://orcid.org/0000-0002-8730-591X

Mestrado em Administração Pública pela Fundação João Pinheiro (FJP). Administradora na Universidade Federal de Minas Gerais. Belo Horizonte, Minas Gerais, Brasil. E-mail: marianasp. adm@gmail.com.

\section{Murilo Cássio Xavier Fahel}

ORCID: https://orcid.org/0000-0003-3889-5017

Pós-Doutor na University of Oxford. Doutorado em Ciências Humanas - Sociologia e Política pela Universidade Federal de Minas Gerais (UFMG). Professor na Universidade Estadual de Montes Claros (Unimontes). Montes Claros, Minas Gerais, Brasil. E-mail: murilo.fahel@ fjp.mg.gov.br. 